\title{
Diabetes-Related Distress Assessment among Type 2 Diabetes Patients
}

\author{
Majed O. Aljuaid $\left(D,{ }^{1}\right.$ Abdulmajeed M. Almutairi, ${ }^{1}$ Mohammed A. Assiri, ${ }^{1}$ \\ Dhifallah M. Almalki, ${ }^{2}$ and Khaled Alswat ${ }^{1}{ }^{1}$ \\ ${ }^{1}$ Taif University School of Medicine, Taif, Saudi Arabia \\ ${ }^{2}$ Diabetes and Endocrinology Center, Prince Mansoure Hospital, Taif, Saudi Arabia \\ Correspondence should be addressed to Khaled Alswat; dr_kswat@hotmail.com
}

Received 7 October 2017; Revised 20 January 2018; Accepted 4 February 2018; Published 25 March 2018

Academic Editor: Eusebio Chiefari

Copyright (C) 2018 Majed O. Aljuaid et al. This is an open access article distributed under the Creative Commons Attribution License, which permits unrestricted use, distribution, and reproduction in any medium, provided the original work is properly cited.

\begin{abstract}
Background and Objectives. Diabetes is one of the most common chronic diseases; it is a debilitating and hard to live with. Diabetesrelated distress (DRD) refers to the emotional and behavioral changes caused by diabetes. Our study aims to assess the prevalence of DRD among type 2 diabetes (T2D) patients using Diabetes Distress Scale-17 items (DDS-17) and its relation to complications and treatment modalities. Methods. A cross-sectional study of adult T2D patients with follow-up visits at the Diabetes and Endocrinology Center in Taif, Saudi Arabia, between January and July 2017. We excluded patients with other forms of diabetes, untreated hypothyroidism, and psychiatric illness. The total score of DDS-17 was calculated by summing the 17 items' results and then dividing the total by 17. If the total score was $>2$, then it was considered as clinically significant results (moderate distress), but if it is $\geq 3$, then it is classified as a high distress. Results. A total of 509 T2D patients with a mean age of $58 \pm 14$ years were included. The majority of participants were male, married, not college educated, and reported a sedentary lifestyle. We found 25\% of the screened T2D patients have moderate to high DRD. Regarding the DRD components, emotional distress was the most prevalent followed by physician-related distress. HabAlc was significantly higher in those with high combined distress and high emotional distress compared to those with mild/moderate distress $(p=0.015$ and 0.030 , resp.). Conclusion. Our study shows that DRD is a medically relevant issue that clinicians need to address. Despite observing a low prevalence of DRD compared to other studies, we found significant correlations between DRD scores and HabA1c, triglyceride levels, BMI, T2D duration, and interval between visits.
\end{abstract}

\section{Background}

Diabetes is one of the most common chronic diseases, estimated to affect more than 400 million people worldwide. Its prevalence is predicted to grow to 642 million by 2040, and it is anticipated to be the 7th leading cause of death by 2030 $[1,2]$. Diabetes will affect more than 70 million in the Middle East and North African region by 2040 [1]. Saudi Arabia and Kuwait are among the countries with the highest prevalence of diabetes, estimated at $17.6 \%$ and $14.3 \%$, respectively [1].

Diabetes is a challenging disease that is considered to be hard to live with as it encompasses a lot of restrictive instructions. The emotional distress facing people with diabetes due to such lifestyle restriction is an area of growing clinical interest [3]. The instructions given by the educator or the physician can seem to be complicated for a person from a nonmedical background, which further compounds the emotional distress of the diagnosis and necessary lifestyle changes $[3,4]$.

Diabetes-related distress (DRD) and diabetes burnout are terms that have been used in the literature to refer to the emotional and behavioral changes caused by diabetes and its demanded lifestyle alterations [5, 6]. Many studies have been conducted in this field using different scales on different populations. These studies have shown that there are many factors related to the presence or absence of DRD, and its severity depends on the characteristics of the population 
TABLE 1: Internal consistency coefficient (Cronbach's alpha) values for Diabetes Distress Scale-17 items (DDS-17).

\begin{tabular}{lc}
\hline DDS-17 items & Cronbach's alpha if item deleted \\
\hline 1. Feeling the diabetes is taking up too much of my mental and physical energy every day & 0.868 \\
2. Feeling that my doctor doesn't know enough about diabetes and diabetes care & 0.877 \\
3. Feeling angry, scared, and/or depressed when I think about living with diabetes & 0.861 \\
4. Feeling that my doctor doesn't give me clear enough directions on how to manage my diabetes & 0.874 \\
5. Feeling that I am not testing my blood sugars frequently enough & 0.873 \\
6. Feeling that I am often failing with my diabetes routine & 0.868 \\
7. Feeling that friends or family are not supportive enough of self-care efforts (e.g., planning activities that \\
conflict with my schedule, encouraging me to eat the "wrong" foods) \\
8. Feeling that diabetes controls my life \\
9. Feeling that my doctor doesn't take my concerns seriously enough \\
10. Not feeling confident in my day-to-day ability to manage diabetes \\
11. Feeling that I will end up with serious long-term complications no matter what I do \\
12. Feeling that I am not sticking closely enough to a good meal plan \\
13. Feeling that friends or family don't appreciate how difficult living with diabetes can be \\
14. Feeling overwhelmed by the demands of living with diabetes \\
15. Feeling that I don't have a doctor, who I can see regularly enough about my diabetes \\
16. Not feeling motivated to keep up my diabetes self-management \\
17. Feeling that friends or family don't give me the emotional support that I would like \\
\hline
\end{tabular}

and other psychosocial factors [7]. The dangerous complications (e.g., hypoglycemia) that can result from DRD have made this issue a growing area of interest for researchers.

A relatively new scale called Diabetes Distress Scale-17 items (DDS-17) was recently developed as a brief and reliable scale that avoids the limitations and deficits of previous metrics [3]. The brief form of DDS is designed for use in clinical settings not just for research purposes [8].

This study was motivated by the scarcity of studies on DRD in Saudi Arabia. To the best of our knowledge, there have been no studies using DDS-17 in this environmental context. Our study aims to assess distress among type 2 diabetes (T2D) patients using DDS-17 and to correlate this $\mathrm{DRD}$ to T2D complications, treatment modalities, and glycemic control.

\section{Methods}

Here, we present a cross-sectional study on T2D patients of the Prince Mansour Hospital, Diabetes, and Endocrinology Center in Taif City, Saudi Arabia, between January and July 2017. All T2D patients were 18 years of age or older, and all recent laboratory results were included. Patients with type 1 diabetes (T1D), untreated hypothyroidism, gestational diabetes, cancer, psychiatric illness, and patients unwilling to participate were excluded.

Researchers reviewed files for the potential patients in clinics and made sure that they fulfilled the inclusion criteria. Data collection forms (DCFs) were compiled during patient interviews using a drug picture chart to help them to identify their treatment correctly. The DCF is composed of three sections: demographic data, past medical history, and drug history. Past history includes history of severe hypoglycemia, which is defined as a decrease of blood sugar less than
$55 \mathrm{mg} / \mathrm{dl}$ with loss of conscious or/and required help from someone else due to their condition in the last 12 months. Laboratory results were collected from patients' electronic medical records. Patient records were anonymized by replacing patient name and medical record number (MRN) with a serial study code prior to export into a statistical analysis program. Our research proposal was reviewed and approved by the Institutional Review Board (IRB) and referenced by H-02-001-16-11-256.

We used DDS-17 to assess DRD in study participants. Each of the 17 items of DDS-17 has a six-point scale for response: a mild to moderate problem is 1 or 2 , a moderate to serious problem is 3 or 4 , and a serious problem is 5 or 6. The total score of DDS-17 was calculated by summing the 17 items' results and dividing by 17 . If the total score was $>2$, then it was considered as clinically significant results (moderate distress), but if it is $\geq 3$, then it is classified as a high distress [3]. DDS-17 assesses four components of DRD, which are emotional, physician-related, regimen-related, and interpersonal distress. Each component scored separately by dividing the sum of its item scores by the number of the items. Patients were considered to have DRD in each component separately if they scored $>2$ in that component.

DDS-17 items were translated to the Arabic language by one bilingual person and validated by another 2 bilingual experts, and it was tested on a pilot sample (100) showing good internal consistency for the whole 17 items as shown in Table 1 (Cronbach's alpha $=0.877$ ).

We could not calculate the sample size of this study due to the absence of an official number of people with T2D in this country. So, we decide to calculate the required sample size based on the approximation process knowing that the IDF estimating the DM in Saudi Arabia by 3.85 million (latest estimation) and the number of population in Saudi 
Arabia was 32.6 million and 556,100 in Taif City. 68,496 was the estimated number of people with diabetes mellitus in Taif City. 596 was the targeted sample size based on the approximation process ( $95 \%$ CI, $5 \%$ margin of error). This number was not corrected for the people with T1D due to the scarcity of information about the burden of this disease. The number of people who were attending the center for their appointment in the diabetes clinics (only 2) was 30 on average (scheduled). This is why we have chosen the convenience sampling method for a specific period (1 month) and included all the people who have an appointment in the center and fulfill the inclusion criteria and intact from the exclusion criteria. Extending the period was done by month in case it was needed till we have reached what was calculated based on the approximation. The extension of the period was due to many reasons:

(1) Discrepancy between the average number and the real number due to many reasons (e.g., vacation)

(2) Significant number of those who have follow-up visits were $\mathrm{T} 1 \mathrm{D}$

(3) High number of those who have other exclusion criteria

The number of people who were recruited was 604 , and 509 was the final number after excluding those with missing values in the DDS- 17 .

For analysis, we used Statistical Package for the Social Sciences (SPSS) program v20. All continuous variables were expressed as mean $\pm \mathrm{SD}$. Categorical variables were compared with the $\chi^{2}$ test and Student's $t$-test for comparing means of continuous variables. One-way ANOVA was used to compare $\geq 3$ means against an independent variable. A $p$ value must be less than 0.05 to be considered statistically significant.

\section{Results}

A total of 509 T2D patients with a mean age of $58 \pm 14$ years were included. The majority of participants were male, married, not college educated, and reported a sedentary lifestyle (Table 2).

Analysis of DDS-17 results indicated that $25 \%$ of our sample have moderate to high DRD based on the total score of the questionnaire. In addition, 54\% of our samples have moderate to high emotional distress, $24.9 \%$ have moderate to high physician-related distress, $12.7 \%$ have moderate to high regimen-related distress, and $7.7 \%$ have moderate to high interpersonal distress.

Examining the differences between the highly distressed and moderately/mildly distressed groups showed significant relationships between the score and age, body mass index (BMI), blood pressure (BP), duration of diabetes, interval between visits of a doctor, and laboratory results (Tables 3-7). Regarding laboratory results, HabAlc was significantly higher in those with high combined distress and high emotional distress compared to those with mild/moderate distress $(p=0.015$ and 0.030 , resp.).
Additionally, LDL was significantly higher in the group with high combined distress compared to that with mild/ moderate combined distress $(p=0.027)$. Longer T2D duration was associated with emotional, physician-related, and regimen-related distress $(p=0.034,0.14$, and 0.026 , resp.). Similarly, the younger patients are more liable to have combined and regimen-related distress $(p=0.027$ and $<0.0001$, resp.).

The means of the total and individual component scores of DDS-17 were analyzed separately (Table 8). Using DDS-17 total scores, we found subjects were more likely to have DRD who were females $(p<0.0001)$, were low income $(p=0.047)$, were unemployed $(p<0.0001)$, have any diabetes complications $(p<0.0001)$, have retinopathy $(p<0.0001)$, have neuropathy $(p=0.015)$, have dyslipidemia $(p=0.025)$, have a family history of T2D $(p=0.052)$, had severe hypoglycemia $(p=0.006)$, and have a history of T2D-related hospital admission $(p=0.001)$.

Those with emotional distress were significantly more likely to be female $(p<0.0001)$, have high income $(p=$ $0.019)$, unemployed $(p<0.0001)$, insulin and oral hypoglycemic drug users $(p=0.006)$, have any diabetic complications $(p<0.0001)$, have retinopathy $(p<0.0001)$, have neuropathy $(p<0.0001)$, have dyslipidemia $(p=0.002)$, have hypertension $(p=0.028)$, have a T2D family history $(p<0.0001)$, have a history of severe hypoglycemia $(p=0.04)$, and have previous T2D-related hospital admissions $(p<0.0001)$.

Physician-related distress score was significantly associated with low income $(p=0.011)$, unemployment $(p=0.038)$, and a history of severe hypoglycemia $(p=0.018)$. In addition, treatment regimen distress was associated with having been divorced $(p<0.0001)$, employed $(p=0.001)$, smoker $(p=0.007)$, insulin and oral hypoglycemic drugs users $(p=0.03)$, peripheral vascular disease $(p=0.018)$, and nephropathy $(p=0.015)$. Nevertheless, those who were female $(p=0.002)$, physicians $(p=0.015)$, unemployed $(p=0.004)$, without a nephropathy history $(p=0.021)$, experienced severe hypoglycemia $(p=0.016)$, and did not have previous T2D-related hospital admissions $(p=0.043)$ were more likely to have high DRD in the interpersonal domain. Also, $p$ values from the one-way ANOVA tests to assess the differences between groups vertically and horizontally are listed in Table 8 . Most of the $p$ values horizontally were significant due to the big differences between emotional distress and the other scores.

Partial correlation adjusting for gender, marital status, level of education, socioeconomic status, employment, treatment modalities, and exercise showed significant correlations between DRD total score and/or DRD component scores with HabA1c, triglyceride levels, BMI, T2D duration, and interval between visits (Table 9).

\section{Discussion}

Our study showed that around $25 \%$ of the participants screened positive for moderate to high DRD on a DDS-17 scale. A study that was done in the USA using the DDS-17 scale showed that $51.3 \%$ of the screened participants have moderate to high DRD [9] Another study in Malaysia revealed 
TABLE 2: Baseline characteristics for the current sample.

\begin{tabular}{|c|c|}
\hline Baseline characteristics & Mean/percentage \\
\hline Age & $58 \pm 14$ \\
\hline DBP & $75.13 \pm 11.21$ \\
\hline SBP & $131.87 \pm 20.72$ \\
\hline BMI & $30.89 \pm 6.96$ \\
\hline Interval between visits & $4.3 \pm 1.8$ \\
\hline Duration of DM in years & $14.19 \pm 8.83$ \\
\hline \multicolumn{2}{|l|}{ Gender } \\
\hline Male & $329(64.6 \%)$ \\
\hline Female & $180(35.4 \%)$ \\
\hline \multicolumn{2}{|l|}{ Marital status } \\
\hline Married & $478(93.9 \%)$ \\
\hline Single & $10(2.0 \%)$ \\
\hline Divorced & $5(1.0 \%)$ \\
\hline Widow & $16(3.1 \%)$ \\
\hline \multicolumn{2}{|l|}{ Level of education } \\
\hline Illiterate & $186(36.6 \%)$ \\
\hline High secondary school or less & $273(53.7 \%)$ \\
\hline Postgraduate education (master or above) & $45(9.1 \%)$ \\
\hline Medical graduate: doctor & $3(0.6 \%)$ \\
\hline \multicolumn{2}{|l|}{ Socioeconomic status } \\
\hline Low (less than 5000 SR) & $153(30.4 \%)$ \\
\hline Medium (5000-15,000 SR) & $319(63.4 \%)$ \\
\hline High (more than 15,000 SR) & $31(6.2 \%)$ \\
\hline \multicolumn{2}{|l|}{ Employment } \\
\hline Unemployed & $165(32.5 \%)$ \\
\hline Employed & $83(16.3 \%)$ \\
\hline Retired/housewife & $260(51.2 \%)$ \\
\hline \multicolumn{2}{|l|}{ Smoking } \\
\hline Yes & $39(8.3 \%)$ \\
\hline No & $358(76.0 \%)$ \\
\hline Former & $74(15.7 \%)$ \\
\hline \multicolumn{2}{|l|}{ Physical activity } \\
\hline Sedentary lifestyle & $253(50.1 \%)$ \\
\hline$<150$ min./week & $166(32.9 \%)$ \\
\hline 150-300 min./week & $75(14.9 \%)$ \\
\hline$>300 \mathrm{~min} . /$ week & $11(2.2 \%)$ \\
\hline \multicolumn{2}{|l|}{ Management } \\
\hline Lifestyle modification & $5(1.0 \%)$ \\
\hline Oral hypoglycemic drugs & $173(34.1 \%)$ \\
\hline Insulin use & $95(18.7 \%)$ \\
\hline Insulin and oral hypoglycemic drugs & $234(46.2 \%)$ \\
\hline \multicolumn{2}{|l|}{ Complications } \\
\hline Yes & $265(55.4 \%)$ \\
\hline No & $213(44.6 \%)$ \\
\hline \multicolumn{2}{|l|}{ Ischemic heart disease } \\
\hline Yes & $29(7.0 \%)$ \\
\hline No & $383(93.0 \%)$ \\
\hline
\end{tabular}

TABLE 2: Continued.

\begin{tabular}{|c|c|}
\hline Baseline characteristics & Mean/percentage \\
\hline \multicolumn{2}{|l|}{ Cerebrovascular accident } \\
\hline Yes & $13(3.3 \%)$ \\
\hline No & $385(96.7 \%)$ \\
\hline \multicolumn{2}{|l|}{ Peripheral vascular disease } \\
\hline Yes & $8(2.0 \%)$ \\
\hline No & $385(98.0 \%)$ \\
\hline \multicolumn{2}{|l|}{ Retinopathy } \\
\hline Yes & $238(45.9 \%)$ \\
\hline No & $281(54.1 \%)$ \\
\hline \multicolumn{2}{|l|}{ Nephropathy } \\
\hline Yes & $59(13.3 \%)$ \\
\hline No & $384(86.7 \%)$ \\
\hline \multicolumn{2}{|l|}{ Neuropathy } \\
\hline Yes & $126(25.6 \%)$ \\
\hline No & $367(74.4 \%)$ \\
\hline \multicolumn{2}{|l|}{ Dyslipidemia/hypercholesterolemia } \\
\hline Yes & $276(58.5 \%)$ \\
\hline No & $196(41.5 \%)$ \\
\hline \multicolumn{2}{|l|}{ Hypertension } \\
\hline Yes & $243(54.7 \%)$ \\
\hline No & $201(45.3 \%)$ \\
\hline \multicolumn{2}{|l|}{ Severe hypoglycemia } \\
\hline Yes & $196(38.5 \%)$ \\
\hline No & $313(61.5 \%)$ \\
\hline \multicolumn{2}{|c|}{ Hospital admission due to diabetes-related conditions } \\
\hline Yes & $79(15.6 \%)$ \\
\hline No & $427(84.4 \%)$ \\
\hline HabAlc & $8.61 \pm 1.95$ \\
\hline Cholesterol & $4.45 \pm 1.08$ \\
\hline Triglyceride & $1.60 \pm 1.18$ \\
\hline HDL & $1.04 \pm 0.29$ \\
\hline LDL & $2.67 \pm 0.92$ \\
\hline Microalbuminuria & $21.28 \pm 83.62$ \\
\hline Total distress score & $1.80 \pm 0.62$ \\
\hline Emotional distress score & $2.47 \pm 1.19$ \\
\hline Physician-related distress score & $1.38 \pm 0.77$ \\
\hline Regimen-related distress score & $1.78 \pm 0.81$ \\
\hline Interpersonal distress score & $1.26 \pm 0.73$ \\
\hline
\end{tabular}

that about $49.2 \%$ of their T2D population has moderate distress on a DDS-17 scale [10]. Similarly, distress proportions were $48.5 \%, 43 \%$, and $39 \%$ in three different studies using DDS-17 from Bangladesh, China, and Canada, respectively [11-13]. On the other hand, two studies from Germany used Problem Areas in Diabetes Questionnaire (PAID) to show that $8.9 \%$ and $10.7 \%$ of their sample were distressed $[14,15]$.

This discrepancy between the previously reported DRD proportions and the DRD prevalence in this study might result from different assessment tools since some of them used PAID. However, for those that used DDS-17, there are 
TABLE 3: The mean \pm SD of age and selected clinical and laboratory variables across the mild-moderate and highly distressed groups (total domain).

\begin{tabular}{lccc}
\hline Clinical/laboratory & \multicolumn{3}{c}{$\begin{array}{c}\text { Result of the total score } \\
\text { (total domain) }\end{array}$} \\
variables & $\begin{array}{c}\text { Yes } \\
\text { Mean } \pm \text { SD }\end{array}$ & $\begin{array}{c}\text { Noan } \pm \text { SD } \\
\text { Mer }\end{array}$ & $p$ value \\
\hline Age & $53 \pm 14$ & $59 \pm 14$ & $0.027^{*}$ \\
Duration of DM & $14.74 \pm 8.06$ & $14.10 \pm 8.91$ & 0.696 \\
in years & $87.07 \pm 21.11$ & $83.22 \pm 17.58$ & 0.270 \\
Weight in kg & $1.597 \pm 0.094$ & $1.642 \pm 0.097$ & $0.018^{*}$ \\
Height in meter & $34.08 \pm 7.85$ & $30.65 \pm 6.93$ & $0.013^{*}$ \\
BMI & $5.3 \pm 1.3$ & $4.3 \pm 1.8$ & $<0.001^{*}$ \\
Interval between & $74.13 \pm 10.64$ & $75.11 \pm 11.29$ & 0.647 \\
visits & $129.13 \pm 18.11$ & $132.02 \pm 20.84$ & 0.459 \\
DBP & $9.74 \pm 1.87$ & $8.56 \pm 1.94$ & $0.015^{*}$ \\
SBP & $1.64 \pm 1.50$ & $1.59 \pm 1.18$ & 0.857 \\
HabA1c & $4.85 \pm 0.91$ & $4.42 \pm 1.07$ & 0.126 \\
Triglyceride & $1.07 \pm 0.30$ & $1.04 \pm 0.29$ & 0.759 \\
Cholesterol & $3.20 \pm 0.78$ & $2.65 \pm 0.91$ & $0.027^{*}$ \\
HDL & $4.25 \pm 6.63$ & $21.77 \pm 86.46$ & 0.466 \\
LDL & & & \\
Microalbuminuria & & & \\
\hline
\end{tabular}

*Statistically significant difference $(p<0.05)$.

TABLE 4: The mean \pm SD of age and selected clinical and laboratory variables across the mild-moderate and highly distressed groups (emotional domain).

\begin{tabular}{|c|c|c|c|}
\hline \multirow{2}{*}{$\begin{array}{l}\text { Clinical/laboratory } \\
\text { variables }\end{array}$} & \multicolumn{3}{|c|}{$\begin{array}{l}\text { Result of the total score } \\
\text { (emotional domain) }\end{array}$} \\
\hline & $\begin{array}{c}\text { Yes } \\
\text { Mean } \pm \text { SD }\end{array}$ & $\begin{array}{c}\text { No } \\
\text { Mean } \pm \text { SD }\end{array}$ & $p$ value \\
\hline Age & $59 \pm 14$ & $58 \pm 14$ & 0.641 \\
\hline $\begin{array}{l}\text { Duration of DM } \\
\text { in years }\end{array}$ & $15.32 \pm 9.21$ & $13.53 \pm 8.60$ & $0.034^{*}$ \\
\hline Weight in $\mathrm{kg}$ & $83.91 \pm 17.49$ & $83.04 \pm 17.82$ & 0.617 \\
\hline Height in meter & $1.613 \pm 0.093$ & $1.652 \pm 0.97$ & $<0.001^{*}$ \\
\hline BMI & $32.25 \pm 6.49$ & $30.12 \pm 7.13$ & $0.002^{*}$ \\
\hline Interval between visits & $4.9 \pm 1.8$ & $4.1 \pm 1.8$ & $<0.001^{*}$ \\
\hline DBP & $75.21 \pm 10.89$ & $75.04 \pm 11.42$ & 0.873 \\
\hline SBP & $134.05 \pm 20.92$ & $130.90 \pm 20.70$ & 0.110 \\
\hline HabA1c & $8.94 \pm 2.10$ & $8.47 \pm 1.86$ & $0.030^{*}$ \\
\hline Triglyceride & $1.50 \pm 0.98$ & $1.64 \pm 1.28$ & 0.245 \\
\hline Cholesterol & $4.42 \pm 0.99$ & $4.45 \pm 1.11$ & 0.817 \\
\hline HDL & $1.05 \pm 0.27$ & $1.04 \pm 0.30$ & 0.743 \\
\hline LDL & $2.67 \pm 0.86$ & $2.67 \pm 0.94$ & 0.996 \\
\hline Microalbuminuria & $32.72 \pm 120.64$ & $15.65 \pm 56.75$ & 0.172 \\
\hline
\end{tabular}

*Statistically significant difference $(p<0.05)$.

many variables that might explain this variation, including big differences between sample sizes. Easy accessibility to the health care centers and free replenishment of drugs could
TABLE 5: The mean \pm SD of age and selected clinical and laboratory variables across the mild-moderate and highly distressed groups (physician-related domain).

\begin{tabular}{lccc}
\hline \multicolumn{1}{c}{$\begin{array}{c}\text { Clinical/laboratory } \\
\text { variables }\end{array}$} & \multicolumn{3}{c}{$\begin{array}{c}\text { Result of the total score } \\
\text { (physician-related domain) }\end{array}$} \\
& Yes & No & Nean \pm SD \\
Age & Mean \pm SD & $p$ value \\
\hline Duration of DM in years & $17.69 \pm 9.15$ & $13.89 \pm 8.77$ & $0.014^{*}$ \\
Weight in kg & $83.90 \pm 20.00$ & $83.49 \pm 17.59$ & 0.905 \\
Height in meter & $1.599 \pm 0.095$ & $1.642 \pm 0.096$ & $0.021^{*}$ \\
BMI & $32.27 \pm 6.82$ & $30.82 \pm 6.98$ & 0.298 \\
Interval between visits & $5.0 \pm 1.5$ & $4.3 \pm 1.8$ & $0.023^{*}$ \\
DBP & $72.26 \pm 9.57$ & $75.38 \pm 11.32$ & 0.113 \\
SBP & $137.57 \pm 20.56$ & $131.40 \pm 20.77$ & $0.040^{*}$ \\
HabA1c & $9.18 \pm 2.04$ & $8.57 \pm 1.94$ & 0.153 \\
Triglyceride & $1.54 \pm 1.24$ & $1.60 \pm 1.19$ & 0.811 \\
Cholesterol & $4.53 \pm 0.68$ & $4.44 \pm 1.10$ & 0.563 \\
HDL & $0.98 \pm 0.25$ & $1.04 \pm 0.29$ & 0.313 \\
LDL & $2.78 \pm 0.69$ & $2.66 \pm 0.93$ & 0.576 \\
Microalbuminuria & $15.33 \pm 27.70$ & $21.16 \pm 86.20$ & 0.769 \\
\hline
\end{tabular}

${ }^{*}$ Statistically significant difference $(p<0.05)$.

TABLE 6: The mean \pm SD of age and selected clinical and laboratory variables across the mild-moderate and highly distressed groups (regimen-related domain).

\begin{tabular}{lccc}
\hline \multirow{2}{*}{$\begin{array}{l}\text { Clinical/laboratory } \\
\text { variables }\end{array}$} & \multicolumn{3}{c}{$\begin{array}{c}\text { Result of the total score } \\
\text { (regimen-related domain) }\end{array}$} \\
& $\begin{array}{c}\text { Yes } \\
\text { Mean } \pm \text { SD }\end{array}$ & $\begin{array}{c}\text { Mean } \pm \text { SD } \\
\text { Age }\end{array}$ & $p$ value \\
\hline $\begin{array}{l}\text { Duration of DM } \\
\text { in years }\end{array}$ & $50 \pm 15$ & $59 \pm 13$ & $<0.001^{*}$ \\
Weight in kg & $11.47 \pm 7.81$ & $14.48 \pm 8.91$ & $0.026^{*}$ \\
Height in meter & $86.52 \pm 21.94$ & $83.27 \pm 17.35$ & 0.271 \\
BMI & $1.636 \pm 0.096$ & $1.640 \pm 0.097$ & 0.821 \\
Interval between visits & $31.75 \pm 10.66$ & $30.81 \pm 6.52$ & 0.586 \\
DBP & $5.4 \pm 1.5$ & $4.2 \pm 1.8$ & $<0.001^{*}$ \\
SBP & $76.85 \pm 10.66$ & $74.98 \pm 11.29$ & 0.279 \\
HabA1c & $131.28 \pm 19.41$ & 131.86 & 0.854 \\
Triglyceride & $9.19 \pm 1.93$ & $8.55 \pm 1.95$ & 0.071 \\
Cholesterol & $1.78 \pm 1.34$ & $1.57 \pm 1.17$ & 0.345 \\
HDL & $4.76 \pm 0.95$ & $4.40 \pm 1.09$ & 0.071 \\
LDL & $1.12 \pm 0.31$ & $1.03 \pm 0.29$ & 0.105 \\
Microalbuminuria & $2.93 \pm 0.80$ & $2.64 \pm 0.93$ & 0.098 \\
\hline
\end{tabular}

*Statistically significant difference $(p<0.05)$.

explain the observed lower prevalence in our study. In particular, this issue was depicted in this study as the lowest mean of the DDS-17 scores being for physician-related and 
TABLE 7: The mean \pm SD of age and selected clinical and laboratory variables across the mild-moderate and highly distressed groups (interpersonal domain).

\begin{tabular}{|c|c|c|c|}
\hline \multirow[b]{2}{*}{ Clinical/laboratory variables } & \multicolumn{3}{|c|}{ Result of the total score (interpersonal domain) } \\
\hline & $\begin{array}{c}\text { Yes } \\
\text { Mean } \pm \text { SD }\end{array}$ & $\begin{array}{c}\text { No } \\
\text { Mean } \pm \text { SD }\end{array}$ & $p$ value \\
\hline Age & $56 \pm 13$ & $58 \pm 14$ & 0.387 \\
\hline Duration of diabetes in years & $12.39 \pm 7.95$ & $14.25 \pm 8.86$ & 0.324 \\
\hline Weight in $\mathrm{kg}$ & $89.62 \pm 22.32$ & $83.11 \pm 17.49$ & 0.109 \\
\hline Height in meter & $1.610 \pm 0.075$ & $1.640 \pm 0.097$ & 0.169 \\
\hline BMI & $32.96 \pm 11.40$ & $30.79 \pm 6.71$ & 0.408 \\
\hline Interval between visits & $5.3 \pm 1.9$ & $4.3 \pm 1.8$ & $0.008^{*}$ \\
\hline DBP & $73.57 \pm 13.19$ & $75.15 \pm 11.07$ & 0.506 \\
\hline SBP & $129.61 \pm 24.72$ & $131.94 \pm 20.55$ & 0.599 \\
\hline HabAlc & $9.42 \pm 2.02$ & $8.59 \pm 1.95$ & 0.149 \\
\hline Triglyceride & $1.37 \pm 1.68$ & $1.61 \pm 1.17$ & 0.485 \\
\hline Cholesterol & $4.61 \pm 0.063$ & $4.44 \pm 1.09$ & 0.637 \\
\hline HDL & $1.05 \pm 0.31$ & $1.04 \pm 0.29$ & 0.880 \\
\hline LDL & $3.20 \pm 0.49$ & $2.66 \pm 0.93$ & 0.085 \\
\hline Microalbuminuria & $5.07 \pm 7.73$ & $21.83 \pm 84.92$ & 0.555 \\
\hline
\end{tabular}

${ }^{*}$ Statistically significant difference $(p<0.05)$.

regimen-related distress after interpersonal distress, while the highest score was emotional.

Demographic data of the participants was useful towards determining the group most affected by DRD. Our study showed many results in line with other studies' results regarding demographic variables (marital status, level of education, income, and employment). Our study showed that marital status was a significant differential factor in one domain (regimen-related) while in a study done in Iran, it correlated with significant differences in all domains of DDS-17 except interpersonal [16]. In our study, the level of education of the participant and the choice of a physician was assessed. These additions proved advantageous as our study revealed that the physician group was a source of high distress on all domains compared to the other groups. Also, lower education level was associated with more distress as reported in the previous study [11]; this finding was similar to ours if we exclude the participated physician. In our study, the low-income group was more affected in two domains only of DRD (physicianrelated and interpersonal). This finding was not in line with a previous study that showed low-income patients were more affected by total distress [11]. The unemployed participants were more likely to have DRD in this study, as found in previous studies $[9,11]$. Our study showed an association between DRD and its components and smoking status, duration of T2D, complications, BMI, management method, and glycemic control. This finding endorsed similar findings from previously published studies $[4,9,10,16,17]$.

Similar to previous studies, our study showed that the duration of diabetes was significantly associated with DRD and three of its domains (emotional, physician-related, and regimen-related) $[3,11]$. This finding is corroborated by two other studies that also found duration to be significantly associated with DRD [3, 11]. Although our study showed a positive correlation between the intervals of the follow-up visits and DRD, this issue was not examined by previous studies to the best of our knowledge.

Our study showed a positive correlation between both the DRD total score and emotional distress with the HabA1c. As expected, this finding was linear to the previous studies' results. [10, 11, 14, 16, 17]. Previous studies have shown a significant correlation between DRD and depression and anxiety $[9,10,17]$. Although we did not screen for psychological factors, they could be related to our observations. It has been shown that improving depressive symptoms has a beneficial effect on HabA1c [18]. However, this effect is mild compared to the effect of improving distress on HabAlclevels, as shown in the interventional study done by Kuniss et al. [19]. This study showed that involving subjects in an educational program at a diabetes clinic can improve glycemic control and correlated with a decrease in DRD. An additional interventional study examined the possibility of improving depressive symptoms in patients with improved $\mathrm{DRD}$, and the authors concluded that DRD is an independent factor that may have an effect on depression [20].

DRD can be measured by both self-reporting methods and biological methods. Biological methods include measuring salivary alpha-amylase, which is considered a good indicator of stress, as it is an indicative of sympathetic nervous system activity. Both methods were used in a study that examined the relationship between DRD and cardiovascular disease (CVD) and concluded that there was a significant relationship between DRD and CVD [21]. These findings are in line with our findings that DRD correlated with worse cardiovascular markers.

This project has three limitations. Firstly, the absence of a previous study in the field renders ours hard to compare to others. Secondly, we were limited by the absence of previous community-based studies that document the number of T2D patients towards determining the sample size for any future 
TABLE 8: DDS scores and subscore mean \pm SD across the demographical and clinical variables when testing these means vertically and horizontally.

\begin{tabular}{|c|c|c|c|c|c|c|}
\hline $\begin{array}{l}\text { Demographical/clinical } \\
\text { variables }\end{array}$ & $\begin{array}{l}\text { Total } \\
\text { score }\end{array}$ & $\begin{array}{l}\text { Emotional } \\
\text { score }\end{array}$ & $\begin{array}{l}\text { Physician-related } \\
\text { score }\end{array}$ & $\begin{array}{l}\text { Regimen-related } \\
\text { score }\end{array}$ & $\begin{array}{l}\text { Interpersonal } \\
\text { score }\end{array}$ & $p$ value \\
\hline \multicolumn{7}{|l|}{ Gender } \\
\hline Male & $1.71 \pm 0.52$ & $2.30 \pm 1.10$ & $1.34 \pm 0.69$ & $1.75 \pm 0.76$ & $1.17 \pm 0.50$ & $<0.0001$ \\
\hline Female & $1.98 \pm 0.74$ & $2.78 \pm 1.28$ & $1.49 \pm 0.92$ & $1.87 \pm 0.90$ & $1.42 \pm 1.01$ & $<0.0001$ \\
\hline$p$ value & $<0.0001$ & $<0.0001$ & 0.062 & 0.116 & 0.002 & \\
\hline \multicolumn{7}{|l|}{ Marital status } \\
\hline Married & $1.80 \pm 0.62$ & $2.47 \pm 1.20$ & $1.39 \pm 0.78$ & $1.77 \pm 0.79$ & $1.26 \pm 0.75$ & $<0.0001$ \\
\hline Single & $1.97 \pm 0.42$ & $2.82 \pm 1.19$ & $1.15 \pm 0.34$ & $2.16 \pm 1.18$ & $1.33 \pm 0.59$ & 0.0003 \\
\hline Divorced & $2.36 \pm 0.54$ & $2.88 \pm 0.76$ & $1.15 \pm 0.34$ & $3.16 \pm 1.15$ & $1.80 \pm 0.61$ & 0.0021 \\
\hline Widow & $1.71 \pm 0.61$ & $2.43 \pm 1.12$ & $1.53 \pm 1.01$ & $1.50 \pm 0.67$ & $1.10 \pm 0.42$ & 0.0004 \\
\hline$p$ value & 0.197 & 0.615 & 0.129 & $<0.0001$ & 0.268 & \\
\hline \multicolumn{7}{|l|}{ Level of education } \\
\hline Illiterate & $1.86 \pm 0.64$ & $2.74 \pm 1.25$ & $1.44 \pm 0.87$ & $1.67 \pm 0.75$ & $1.27 \pm 0.84$ & $<0.0001$ \\
\hline $\begin{array}{l}\text { High secondary school } \\
\text { or less }\end{array}$ & $1.75 \pm 0.60$ & $2.26 \pm 1.09$ & $1.37 \pm 0.71$ & $1.83 \pm 0.83$ & $1.26 \pm 0.70$ & $<0.0001$ \\
\hline $\begin{array}{l}\text { Postgraduate education } \\
\text { (master or above) }\end{array}$ & $1.80 \pm 0.50$ & $2.50 \pm 1.18$ & $1.28 \pm 0.70$ & $1.88 \pm 0.73$ & $1.16 \pm 0.41$ & $<0.0001$ \\
\hline Doctor & $2.51 \pm 1.09$ & $3.40 \pm 1.44$ & $2.08 \pm 1.28$ & $2.07 \pm 0.70$ & $2.33 \pm 1.15$ & 0.6652 \\
\hline$p$ value & 0.165 & 0.273 & 0.350 & 0.073 & 0.015 & \\
\hline \multicolumn{7}{|l|}{ Socioeconomic status } \\
\hline Low (less than 5000 SR) & $1.94 \pm 0.72$ & $2.58 \pm 1.20$ & $1.60 \pm 0.99$ & $1.91 \pm 0.89$ & $1.39 \pm 0.97$ & $<0.0001$ \\
\hline Medium (5000-15,000 SR) & $1.72 \pm 0.55$ & $2.39 \pm 1.18$ & $1.29 \pm 0.64$ & $1.71 \pm 0.75$ & $1.18 \pm 0.58$ & $<0.0001$ \\
\hline High (more than 15,000 SR) & $2.00 \pm 0.64$ & $2.88 \pm 1.19$ & $1.43 \pm 0.81$ & $1.94 \pm 0.94$ & $1.38 \pm 0.70$ & $<0.0001$ \\
\hline$p$ value & 0.047 & 0.019 & 0.011 & 0.296 & 0.189 & \\
\hline \multicolumn{7}{|l|}{ Employment } \\
\hline Unemployed & $1.99 \pm 0.69$ & $2.80 \pm 1.23$ & $1.52 \pm 0.94$ & $1.86 \pm 0.86$ & $1.43 \pm 1.03$ & $<0.0001$ \\
\hline Employed & $1.84 \pm 0.72$ & $2.51 \pm 1.31$ & $1.41 \pm 0.78$ & $1.92 \pm 0.93$ & $1.21 \pm 0.51$ & $<0.0001$ \\
\hline Retired/housewife & $1.67 \pm 0.49$ & $2.26 \pm 1.08$ & $1.31 \pm 0.64$ & $1.69 \pm 0.73$ & $1.17 \pm 0.52$ & $<0.0001$ \\
\hline$p$ value & $<0.0001$ & $<0.0001$ & 0.038 & 0.001 & 0.004 & \\
\hline \multicolumn{7}{|l|}{ Smoking } \\
\hline Yes & $1.81 \pm 0.61$ & $2.59 \pm 1.21$ & $1.27 \pm 0.61$ & $1.90 \pm 0.98$ & $1.05 \pm 0.16$ & $<0.0001$ \\
\hline No & $1.80 \pm 0.64$ & $2.52 \pm 1.24$ & $1.40 \pm 0.80$ & $1.70 \pm 0.78$ & $1.30 \pm 0.82$ & $<0.0001$ \\
\hline Former & $1.80 \pm 0.55$ & $2.27 \pm 0.99$ & $1.46 \pm 0.78$ & $1.97 \pm 0.80$ & $1.18 \pm 0.52$ & $<0.0001$ \\
\hline$p$ value & 0.105 & 0.293 & 0.263 & 0.007 & 0.565 & \\
\hline \multicolumn{7}{|l|}{ Physical activity } \\
\hline Sedentary lifestyle & $1.86 \pm 0.66$ & $2.64 \pm 1.23$ & $1.44 \pm 0.83$ & $1.74 \pm 0.86$ & $1.33 \pm 0.82$ & $<0.0001$ \\
\hline$<150 \mathrm{~min}$./week & $1.79 \pm 0.61$ & $2.37 \pm 1.15$ & $1.36 \pm 0.73$ & $1.88 \pm 0.80$ & $1.27 \pm 0.75$ & $<0.0001$ \\
\hline 150-300 min./week & $1.64 \pm 0.50$ & $2.20 \pm 1.11$ & $1.28 \pm 0.68$ & $1.70 \pm 0.67$ & $1.05 \pm 0.23$ & $<0.0001$ \\
\hline$>300 \mathrm{~min}$./week & $1.47 \pm 0.35$ & $1.96 \pm 0.78$ & $1.25 \pm 0.71$ & $1.48 \pm 0.33$ & $1.06 \pm 0.20$ & $<0.0001$ \\
\hline$p$ value & 0.166 & 0.204 & 0.470 & 0.506 & 0.191 & \\
\hline \multicolumn{7}{|l|}{ Management } \\
\hline Lifestyle modification & $1.44 \pm 0.32$ & $1.88 \pm 1.14$ & $1.15 \pm 0.34$ & $1.44 \pm 0.59$ & $1.07 \pm 0.15$ & 0.2851 \\
\hline Oral hypoglycemic drugs & $1.70 \pm 0.55$ & $2.29 \pm 1.12$ & $1.38 \pm 0.76$ & $1.68 \pm 0.76$ & $1.21 \pm 0.51$ & $<0.0001$ \\
\hline Insulin use & $1.88 \pm 0.53$ & $2.69 \pm 1.09$ & $1.51 \pm 0.89$ & $1.73 \pm 0.81$ & $1.23 \pm 0.72$ & $<0.0001$ \\
\hline $\begin{array}{l}\text { Insulin and oral } \\
\text { hypoglycemic drugs }\end{array}$ & $1.86 \pm 0.69$ & $2.53 \pm 1.27$ & $1.35 \pm 0.73$ & $1.89 \pm 0.85$ & $1.32 \pm 0.88$ & $<0.0001$ \\
\hline$p$ value & 0.132 & 0.006 & 0.117 & 0.030 & 0.297 & \\
\hline
\end{tabular}


TABle 8: Continued.

\begin{tabular}{|c|c|c|c|c|c|c|}
\hline $\begin{array}{l}\text { Demographical/clinical } \\
\text { variables }\end{array}$ & $\begin{array}{l}\text { Total } \\
\text { score }\end{array}$ & $\begin{array}{l}\text { Emotional } \\
\text { score }\end{array}$ & $\begin{array}{c}\text { Physician-related } \\
\text { score }\end{array}$ & $\begin{array}{l}\text { Regimen-related } \\
\text { score }\end{array}$ & $\begin{array}{l}\text { Interpersonal } \\
\text { score }\end{array}$ & $p$ value \\
\hline \multicolumn{7}{|l|}{ Complications } \\
\hline Yes & $1.92 \pm 0.63$ & $2.85 \pm 1.24$ & $1.39 \pm 0.85$ & $1.80 \pm 0.82$ & $1.29 \pm 0.80$ & $<0.0001$ \\
\hline No & $1.67 \pm 0.59$ & $2.05 \pm 1.02$ & $1.40 \pm 0.70$ & $1.75 \pm 0.79$ & $1.25 \pm 0.69$ & $<0.0001$ \\
\hline$p$ value & $<0.0001$ & $<0.0001$ & 0.827 & 0.553 & 0.534 & \\
\hline \multicolumn{7}{|l|}{ Ischemic heart disease } \\
\hline Yes & $1.97 \pm 0.64$ & $2.72 \pm 1.32$ & $1.59 \pm 1.14$ & $1.93 \pm 0.54$ & $1.28 \pm 0.54$ & $<0.0001$ \\
\hline No & $1.76 \pm 0.64$ & $2.30 \pm 1.15$ & $1.40 \pm 0.76$ & $1.79 \pm 0.83$ & $1.30 \pm 0.79$ & $<0.0001$ \\
\hline$p$ value & 0.098 & 0.056 & 0.384 & 0.354 & 0.890 & \\
\hline \multicolumn{7}{|l|}{ Cerebral vascular accident } \\
\hline Yes & $1.89 \pm 0.59$ & $2.48 \pm 1.14$ & $1.48 \pm 1.04$ & $1.94 \pm 0.78$ & $1.38 \pm 0.88$ & 0.0257 \\
\hline No & $1.76 \pm 0.64$ & $2.30 \pm 1.15$ & $1.39 \pm 0.76$ & $1.79 \pm 0.83$ & $1.30 \pm 0.79$ & $<0.0001$ \\
\hline$p$ value & 0.473 & 0.577 & 0.681 & 0.522 & 0.689 & \\
\hline \multicolumn{7}{|c|}{ Peripheral vascular disease } \\
\hline Yes & $2.36 \pm 0.91$ & $3.05 \pm 1.78$ & $2.16 \pm 1.71$ & $2.48 \pm 1.28$ & $1.29 \pm 0.49$ & 0.1408 \\
\hline No & $1.76 \pm 0.63$ & $2.29 \pm 1.13$ & $1.39 \pm 0.76$ & $1.78 \pm 0.81$ & $1.30 \pm 0.79$ & $<0.0001$ \\
\hline$p$ value & 0.104 & 0.266 & 0.249 & 0.018 & 0.708 & \\
\hline \multicolumn{7}{|l|}{ Retinopathy } \\
\hline Yes & $1.91 \pm 0.62$ & $2.86 \pm 1.20$ & $1.41 \pm 0.88$ & $1.75 \pm 0.79$ & $1.27 \pm 0.80$ & $<0.0001$ \\
\hline No & $1.70 \pm 0.60$ & $2.13 \pm 1.06$ & $1.36 \pm 0.68$ & $1.81 \pm 0.82$ & $1.24 \pm 0.65$ & $<0.0001$ \\
\hline$p$ value & $<0.0001$ & $<0.0001$ & 0.490 & 0.396 & 0.708 & \\
\hline \multicolumn{7}{|l|}{ Nephropathy } \\
\hline Yes & $1.90 \pm 0.54$ & $2.49 \pm 1.08$ & $1.52 \pm 0.93$ & $2.07 \pm 0.70$ & $1.13 \pm 0.42$ & $<0.0001$ \\
\hline No & $1.76 \pm 0.64$ & $2.30 \pm 1.15$ & $1.40 \pm 0.76$ & $1.79 \pm 0.83$ & $1.29 \pm 0.79$ & $<0.0001$ \\
\hline$p$ value & 0.135 & 0.255 & 0.332 & 0.015 & 0.021 & \\
\hline \multicolumn{7}{|l|}{ Neuropathy } \\
\hline Yes & $1.91 \pm 0.52$ & $2.94 \pm 1.12$ & $1.33 \pm 0.78$ & $1.78 \pm 0.78$ & $1.17 \pm 0.55$ & $<0.0001$ \\
\hline No & $1.76 \pm 0.65$ & $2.30 \pm 1.15$ & $1.40 \pm 0.77$ & $1.78 \pm 0.84$ & $1.29 \pm 0.80$ & $<0.0001$ \\
\hline$p$ value & 0.015 & $<0.0001$ & 0.401 & 0.981 & 0.068 & \\
\hline \multicolumn{7}{|l|}{ Dyslipidemia } \\
\hline Yes & $1.87 \pm 0.65$ & $2.62 \pm 1.20$ & $1.38 \pm 0.82$ & $1.87 \pm 0.85$ & $1.29 \pm 0.82$ & $<0.0001$ \\
\hline No & $1.74 \pm 0.61$ & $2.27 \pm 1.18$ & $1.41 \pm 0.77$ & $1.72 \pm 0.79$ & $1.28 \pm 0.68$ & $<0.0001$ \\
\hline$p$ value & 0.025 & 0.002 & 0.658 & 0.060 & 0.882 & \\
\hline \multicolumn{7}{|l|}{ Hypertension } \\
\hline Yes & $1.84 \pm 0.64$ & $2.57 \pm 1.24$ & $1.43 \pm 0.82$ & $1.78 \pm 0.80$ & $1.24 \pm 0.73$ & $<0.0001$ \\
\hline No & $1.74 \pm 0.60$ & $2.31 \pm 1.16$ & $1.38 \pm 0.76$ & $1.77 \pm 0.82$ & $1.25 \pm 0.69$ & $<0.0001$ \\
\hline$p$ value & 0.125 & 0.028 & 0.524 & 0.956 & 0.854 & \\
\hline \multicolumn{7}{|l|}{ Family history } \\
\hline Yes & $1.83 \pm 0.62$ & $2.58 \pm 1.20$ & $1.38 \pm 0.78$ & $1.78 \pm 0.80$ & $1.26 \pm 0.75$ & $<0.0001$ \\
\hline No & $1.69 \pm 0.62$ & $2.04 \pm 1.01$ & $1.38 \pm 0.73$ & $1.84 \pm 0.86$ & $1.31 \pm 0.72$ & $<0.0001$ \\
\hline$p$ value & 0.052 & $<0.0001$ & 0.9848 & 0.521 & 0.581 & \\
\hline \multicolumn{7}{|l|}{ Severe hypoglycemia } \\
\hline Yes & $1.90 \pm 0.67$ & $2.61 \pm 1.23$ & $1.50 \pm 0.90$ & $1.81 \pm 0.79$ & $1.37 \pm 0.94$ & $<0.001$ \\
\hline No & $1.74 \pm 0.58$ & $2.39 \pm 1.16$ & $1.32 \pm 0.69$ & $1.77 \pm 0.83$ & $1.19 \pm 0.56$ & $<0.0001$ \\
\hline$p$ value & 0.006 & 0.040 & 0.018 & 0.565 & 0.016 & \\
\hline \multicolumn{7}{|l|}{ Hospital admission } \\
\hline Yes & $2.04 \pm 0.68$ & $2.91 \pm 1.33$ & $1.52 \pm 1.00$ & $1.93 \pm 0.79$ & $1.47 \pm 0.1 .03$ & $<0.0001$ \\
\hline No & $1.76 \pm 0.59$ & $2.39 \pm 1.15$ & $1.37 \pm 0.73$ & $1.75 \pm 0.79$ & $1.22 \pm 0.66$ & $<0.0001$ \\
\hline$p$ value & 0.001 & $<0.0001$ & 0.200 & 0.061 & 0.043 & \\
\hline
\end{tabular}


TABLE 9: Partial correlation adjusting for gender, marital status, level of educations, socioeconomic status, employment, treatment modalities, and exercise.

\begin{tabular}{|c|c|c|c|c|c|c|}
\hline Clinical/laboratory variables & & $T$-score & $E$-score & PR-score & RR-score & IP-score \\
\hline \multirow{2}{*}{ Triglyceride } & Pearson coefficient $(r)$ & -0.079 & -0.112 & -0.004 & -0.025 & -0.015 \\
\hline & $p$ value & 0.132 & 0.032 & 0.943 & 0.634 & 0.774 \\
\hline \multirow{2}{*}{ Cholesterol } & Pearson coefficient $(r)$ & 0.023 & -0.027 & 0.026 & 0.051 & 0.029 \\
\hline & $p$ value & 0.674 & 0.622 & 0.637 & 0.355 & 0.591 \\
\hline \multirow{2}{*}{ HDL } & Pearson coefficient $(r)$ & -0.089 & -0.092 & -0.066 & -0.027 & -0.052 \\
\hline & $p$ value & 0.115 & 0.104 & 0.241 & 0.638 & 0.360 \\
\hline \multirow{2}{*}{ LDL } & Pearson coefficient $(r)$ & 0.046 & 0.004 & 0.026 & 0.042 & 0.081 \\
\hline & $p$ value & 0.404 & 0.942 & 0.639 & 0.444 & 0.138 \\
\hline \multirow{2}{*}{ Microalbuminuria } & Pearson coefficient $(r)$ & 0.023 & 0.068 & -0.057 & 0.025 & -0.056 \\
\hline & $p$ value & 0.701 & 0.250 & 0.337 & 0.670 & 0.345 \\
\hline \multirow{2}{*}{ HabAlc } & Pearson coefficient $(r)$ & 0.118 & 0.106 & 0.079 & 0.072 & 0.032 \\
\hline & $p$ value & 0.029 & 0.050 & 0.148 & 0.185 & 0.560 \\
\hline \multirow{2}{*}{ BMI } & Pearson coefficient $(r)$ & 0.079 & 0.097 & -0.024 & 0.070 & 0.018 \\
\hline & $p$ value & 0.102 & 0.043 & 0.621 & 0.142 & 0.704 \\
\hline \multirow{2}{*}{ Duration of diabetes in years } & Pearson coefficient $(r)$ & 0.092 & 0.098 & 0.150 & -0.037 & -0.040 \\
\hline & $p$ value & 0.048 & 0.032 & 0.001 & 0.417 & 0.383 \\
\hline \multirow{2}{*}{ Interval between visits } & Pearson coefficient $(r)$ & 0.159 & 0.115 & 0.061 & 0.165 & 0.078 \\
\hline & $p$ value & 0.001 & 0.017 & 0.205 & 0.001 & 0.104 \\
\hline \multirow{2}{*}{ Age } & Pearson coefficient $(r)$ & -0.029 & -0.028 & 0.063 & -0.080 & -0.001 \\
\hline & $p$ value & 0.537 & 0.545 & 0.168 & 0.078 & 0.990 \\
\hline
\end{tabular}

projects. Thirdly, this is a single-center study and we believe a multicenter one is required to investigate this problem nationwide, similar to the Diabetes Attitude, Wishes and Needs (DAWN) projects [22, 23].

\section{Conclusions and Recommendations}

Our study shows that DRD is a medically relevant issue that clinicians need to address to successfully manage T2D. The associations found in this study mirrored those found in previous studies and further endorsed the need for clinical attention to DRD, especially in societies with a high prevalence of T2D. This study demonstrates a low prevalence of DRD compared to the majority of other studies. We observed significant correlations between DRD total score and/or DRD components scores with HabAlc, triglyceride levels, BMI, T2D duration, and interval between visits. DRD has an effect on glycemic control as shown in this study and previous studies $[10,11,14,16,17]$ So, it is a considerably important issue that has to be taken in caring the people with diabetes. The suggested management strategies are as follows:

(1) Screen for the DRD by the 2-item DDS.

(2) Screen the 4 components if it is needed (distressed patients on the DDS-2) by the DDS-17.

(3) Offer help for them and engage their family into the management plan and exclude other causes for distress (if known from the past medical history). (i) Management plan: this includes boosting the selfcare practices and coping skills [24].

(4) Monitor the glycemic control by the HabA1c (if needed as a baseline).

(5) Monitor the adherence to the newly applied methods that were used to alleviate the DRD.

(6) Screen them every 3 months accompanied by HabA1c (if it was affected in the last visit).

Also, we recommend future interventional studies to be made, in order to determine the best approaches for a physician to prevent and treat distressed patients and to apply these approaches in our Eastern society.

\section{Conflicts of Interest}

The authors declare that they have no conflicts of interest.

\section{Acknowledgments}

The authors would like to thank the nurses of the Diabetes and Endocrinology Center of Prince Mansour Military Hospital for their assistance in the current work.

\section{References}

[1] K. Ogurtsova, J. D. da Rocha Fernandes, Y. Huang et al., "IDF Diabetes Atlas: global estimates for the prevalence of diabetes for 2015 and 2040," Diabetes Research and Clinical Practice, vol. 128, pp. 40-50, 2017. 
[2] C. D. Mathers and D. Loncar, "Projections of global mortality and burden of disease from 2002 to 2030," PLoS Medicine, vol. 3, no. 11, article e442, 2006.

[3] W. H. Polonsky, L. Fisher, J. Earles et al., “Assessing psychosocial sistress in diabetes: development of the Diabetes Distress Scale," Diabetes Care, vol. 28, no. 3, pp. 626-631, 2005.

[4] B.-H. Chew, S. Mohd-Sidik, and S. Shariff-Ghazali, "Negative effects of diabetes-related distress on health-related quality of life: an evaluation among the adult patients with type 2 diabetes mellitus in three primary healthcare clinics in Malaysia," Health and Quality of Life Outcomes, vol. 13, no. 1, p. 187, 2015.

[5] L. Fisher, W. H. Polonsky, D. M. Hessler et al., "Understanding the sources of diabetes distress in adults with type 1 diabetes," Journal of Diabetes and its Complications, vol. 29, no. 4, pp. 572-577, 2015.

[6] C. Fritschi and L. Quinn, "Fatigue in patients with diabetes: a review," Journal of Psychosomatic Research, vol. 69, no. 1, pp. 33-41, 2010.

[7] E. Berry, S. Lockhart, M. Davies, J. R. Lindsay, and M. Dempster, "Diabetes distress: understanding the hidden struggles of living with diabetes and exploring intervention strategies," Postgraduate Medical Journal, vol. 91, no. 1075, pp. 278-283, 2015.

[8] L. Fisher, R. E. Glasgow, J. T. Mullan, M. M. Skaff, and W. H. Polonsky, "Development of a brief diabetes distress screening instrument," The Annals of Family Medicine, vol. 6, no. 3, pp. 246-252, 2008.

[9] L. Fisher, R. E. Glasgow, and L. A. Strycker, "The relationship between diabetes distress and clinical depression with glycemic control among patients with type 2 diabetes," Diabetes Care, vol. 33, no. 5, pp. 1034-1036, 2010.

[10] B.-H. Chew, R. Vos, S. Mohd-Sidik, and G. E. H. M. Rutten, "Diabetes-related distress, depression and distress-depression among adults with type 2 diabetes mellitus in Malaysia," PLoS One, vol. 11, no. 3, article e0152095, 2016.

[11] M. Islam, M. Karim, S. Habib, and K. Yesmin, "Diabetes distress among type 2 diabetic patients," International Journal of Medicine and Biomedical Research, vol. 2, no. 2, pp. 113124, 2013.

[12] H. Zhou, J. Zhu, L. Liu et al., "Diabetes-related distress and its associated factors among patients with type 2 diabetes mellitus in China," Psychiatry Research, vol. 252, pp. 45-50, 2017.

[13] E. M. Wong, R. Afshar, H. Qian, M. Zhang, T. G. Elliott, and T. S. Tang, "Diabetes distress, depression and glycemic control in a Canadian-based specialty care setting," Canadian Journal of Diabetes, vol. 41, no. 4, pp. 362-365, 2017.

[14] N. Kuniss, T. Rechtacek, C. Kloos et al., "Diabetes-related burden and distress in people with diabetes mellitus at primary care level in Germany," Acta Diabetologica, vol. 54, no. 5, pp. 471-478, 2017.

[15] N. Kuniss, G. Kramer, N. Müller et al., "Diabetes-related burden and distress is low in people with diabetes at outpatient tertiary care level," Experimental and Clinical Endocrinology \& Diabetes, vol. 124, no. 05, pp. 307-312, 2016.

[16] A. Tol, A. Baghbanian, G. Sharifirad et al., "Assessment of diabetic distress and disease related factors in patients with type 2 diabetes in Isfahan: a way to tailor an effective intervention planning in Isfahan-Iran," Journal of Diabetes \& Metabolic Disorders, vol. 11, no. 1, p. 20, 2012.

[17] S. Reza Alvani, N. Mohd Zaharim, and L. Wynne Kimura, "Defining the relationship of psychological well-being and diabetes distress with glycemic control among Malaysian type 2 diabetes," Practice in Clinical Psychology, vol. 3, no. 3, pp. 167-176, 2016.

[18] L. E. Egede, "Effects of depression on work loss and disability bed days in individuals with diabetes," Diabetes Care, vol. 27, no. 7, pp. 1751-1753, 2004.

[19] N. Kuniss, U. Müller, C. Kloos, G. Wolf, and G. Kramer, "Reduction of HbAlc and diabetes-related distress after intervention in a diabetes day care clinic in people with type 2 diabetes but not with type 1 diabetes," Experimental and Clinical Endocrinology \& Diabetes, 2017.

[20] A. Reimer, A. Schmitt, D. Ehrmann, B. Kulzer, and N. Hermanns, "Reduction of diabetes-related distress predicts improved depressive symptoms: a secondary analysis of the DIAMOS study," PLoS One, vol. 12, no. 7, article e0181218, 2017.

[21] E. Gideon VBrodie, "Association of biological and selfreported stress measures with cardiovascular disease and risk factors among adults with type II diabetes mellitus," in Proceedings of The National Conferences On Undergraduate Research (NCUR) 2014, pp. 204-215, University of Kentucky, Lexington, 2014.

[22] M. M. Funnell, "The Diabetes Attitudes, Wishes, and Needs (DAWN) study," Clinical Diabetes, vol. 24, no. 4, pp. 154155, 2006.

[23] A. Nicolucci, K. Kovacs Burns, R. I. G. Holt et al., "Diabetes Attitudes, Wishes and Needs second study (DAWN2 ${ }^{\mathrm{TM}}$ ): cross-national benchmarking of diabetes-related psychosocial outcomes for people with diabetes," Diabetic Medicine, vol. 30, no. 7, pp. 767-777, 2013.

[24] S. Kalra, K. Verma, and Y. Balhara, "Management of diabetes distress," Journal of Pakistan Medical Association, vol. 67, no. 10, pp. 1625-1627, 2017. 


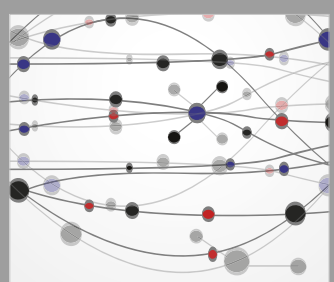

The Scientific World Journal
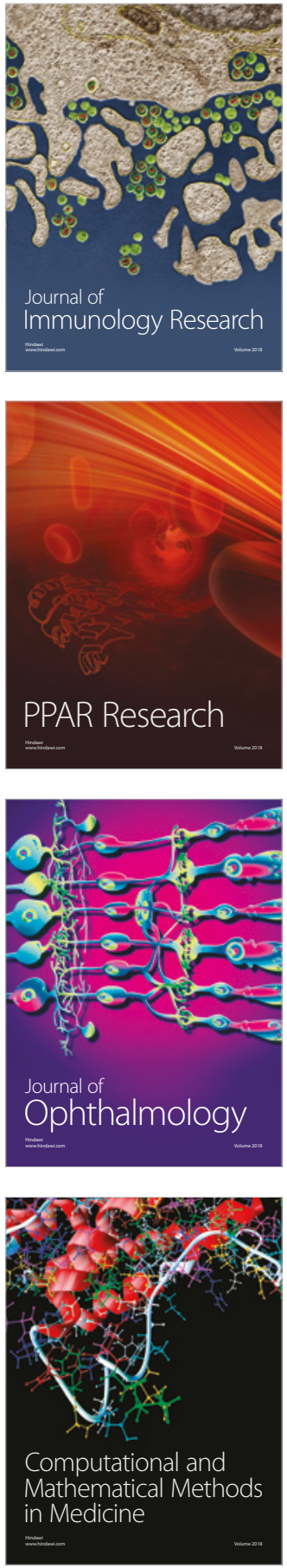



Gastroenterology Research and Practice

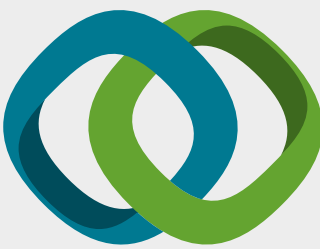

\section{Hindawi}

Submit your manuscripts at

www.hindawi.com
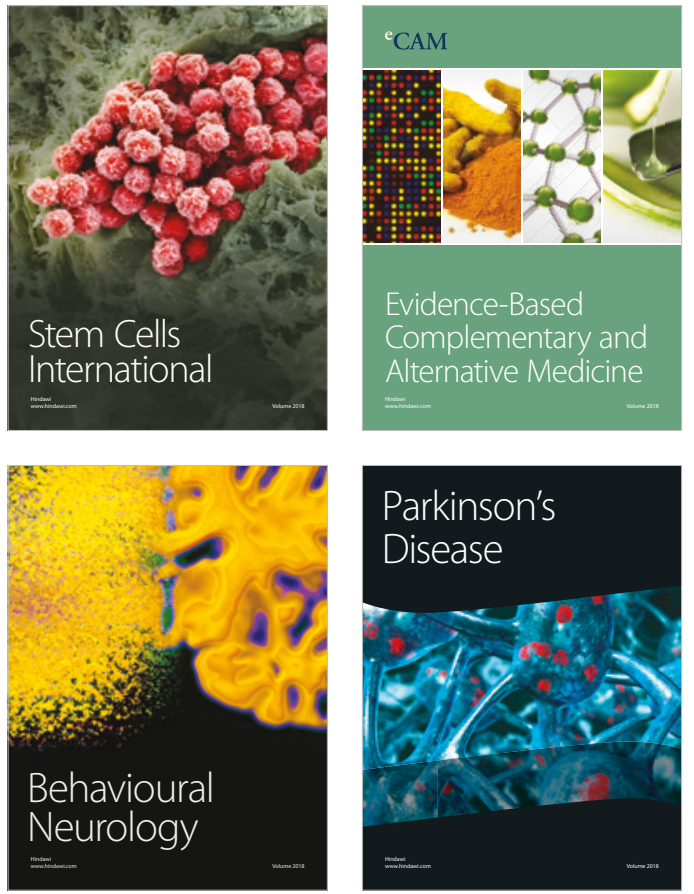

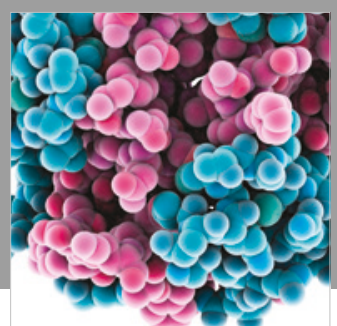

ournal of

Diabetes Research

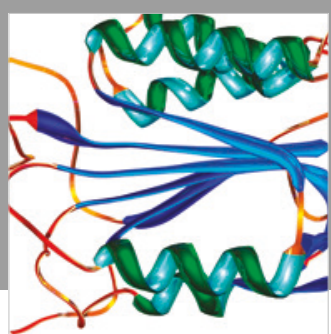

Disease Markers
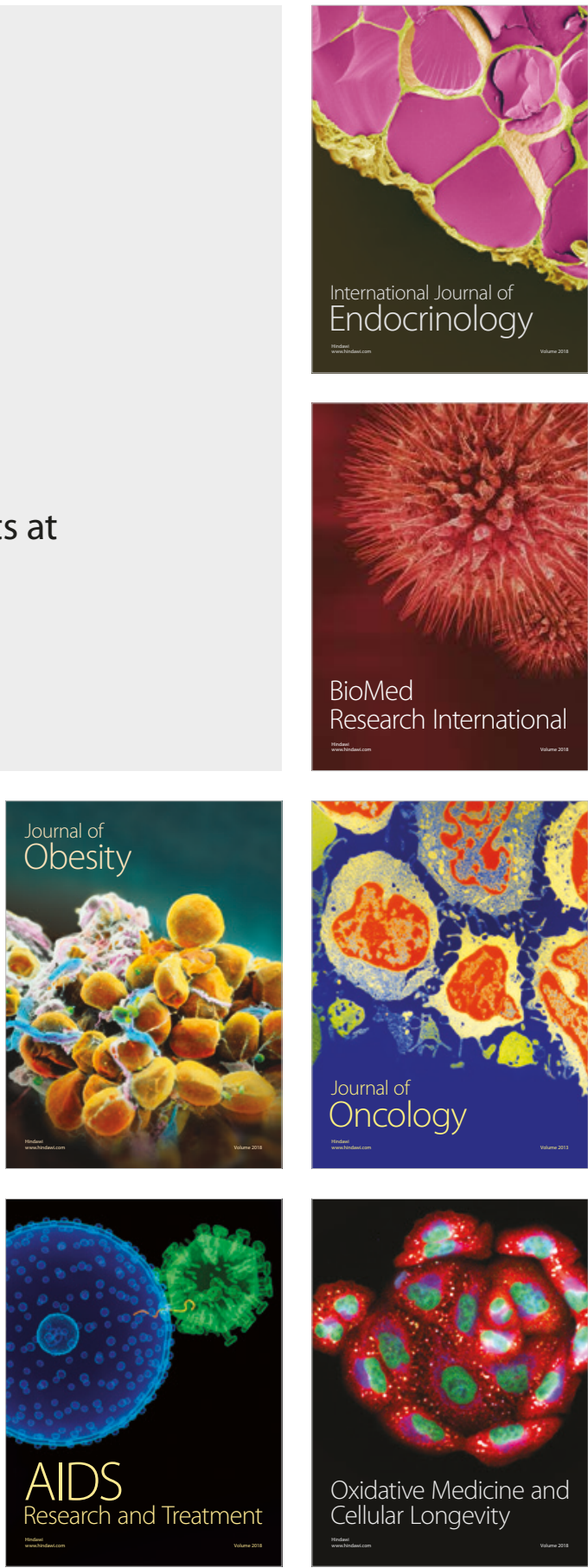